\title{
A Framework for Official Temporary Population Statistics
}

\author{
Elin Charles-Edwards ${ }^{1}$, Martin Bell ${ }^{1}$, Radoslaw Panczak ${ }^{1}$, \\ and Jonathan Corcoran ${ }^{1}$
}

\begin{abstract}
There is considerable demand for official statistics on temporary populations to supplement statistics on resident and working populations. Progress has been slow, with temporary population statistics not part of the standard suite of measures produced by national statistical offices. This article adopts the framework for official statistics proposed by Raymer and colleagues as a guide to aspects relating to society, concepts, data, processing, outputs and validation. The article proposes a conceptual framework linking temporary population mobility, defined as a move more than one night in duration that does not entail a change in usual residence, and temporary populations. Using Australia as an example, we discuss various dimensions of temporary mobility that complicate its measurement. We then report the outcomes of a survey of user needs for temporary population statistics along with a desktop review of OECD countries to identify the best formulation of temporary population statistics, and current international practice respectively. The article concludes by proposing two related concepts for temporary populations: population present and person-time, which overcome a number of issues currently impeding progress in this area and discuss their potential implementation.
\end{abstract}

Key words: Seasonal; ambient; mobility; estimates.

\section{Introduction}

Accurate and timely population statistics are fundamental to understanding society. Official statistics take a range of forms, reflecting different population concepts, varying data availability, and changing societal needs (Raymer et al. 2015). The two most commonly produced forms of population statistics are de jure counts, which measure the population usually resident in an area at a particular point in time, and de facto counts, which capture the population present in an area. Both de jure and de facto estimates tend to capture a snapshot of populations at a single point in time, and miss the daily, weekly and seasonal flux in populations that are driven by diurnal and temporary population movements. There is an established demand for estimates that account for short-term shifts in populations to serve as the denominator for health, crime and other statistics, to

\footnotetext{
${ }^{1}$ The University of Queensland, St Lucia, Brisbane, Australia, 4072. Emails: e.charles-edwards@uq.edu.au, martin.bell@uq.edu.au,r.panczak@uq.edu.au and jj.corcoran@uq.edu.au

Acknowledgments: The authors wish to thank the Australian Bureau of Statistics (ABS) for facilitating the collection of data on which the paper is based. However, the interpretations of the analysis are solely those of the authors and do not necessarily reflect the views and opinions of the ABS or any of their employees. This research was funded by the Australian Government through the Australian Research Council Linkage project scheme, LP160100305.
} 
assist in emergency preparedness and response, and for the planning and provision of local goods and services (Smith 1989; Deville et al. 2014; Kounadi et al. 2018). The United Nations (2017) has called for estimates of temporary or service populations "if a population present count or usual resident population count does not accurately represent the demand for, or provision of services in a country or part of a country" (United Nations 2017, 180). Improved data availability, particularly from mobile phones and related technologies, has led to an increased interest in enumerating short-term population change. However, such estimates have been produced outside of official statistical frameworks, often for a single area, and intermittently. Despite their importance as a complement to common population statistics, few statistical agencies currently produce official temporary population estimates, and it remains unclear how such estimates are best conceptualised and generated.

This article explores issues associated with the production of official temporary population statistics. The production of estimates is complex due to variability in the nature and dynamics of the underlying mobility driving short-term shifts in population numbers, a lack of clarity with respect to user needs, limited data availability and nascent conceptual development. We seek to advance the field of temporary population estimates by systematically exploring these issues, and through this process, provide greater conceptual clarity on the formulation of estimates. We begin in Section 2 with a discussion of the spatiotemporal dynamics of various forms of temporary population mobility and their impacts on temporary populations, using Australia as a case study. Understanding the dynamics of mobility is an essential prerequisite to the production of a robust and useful suite of measures of temporary populations. While statistics must be responsive to national contexts, Australia offers a useful testbed, since it features both the diverse forms of mobility and the differing types of data that are commonly found in developed countries.

In Section 3, we report the results of a survey of Australian government officials and planners as to their requirements for temporary population statistics. We then examine currently published outputs of temporary population statistics in a number of OECD countries in Section 4, before concluding by outlining a consistent conceptual basis for temporary population statistics.

\section{Temporary Mobility in Australia}

Temporary population mobility can be defined as displacements from a usual residence which are one night or more in duration but do not entail a change in usual residence. Academic interest in temporary population mobility is longstanding (Chapman and Prothero 1983). Early research was directed at temporary mobility in the developing world, where temporary mobility was viewed as both a customary process and as a means of adapting to transformations brought about by colonisation and industrialisation (Chapman 1978; Chapman and Prothero 1983; Prothero and Chapman 1985; Mitchell 1969; Taylor 1986). Not until later did researchers in the developed world turn to the study of temporary population mobility, spurred by Zelinsky's $(1971,230)$ 'Hypothesis of the Mobility Transition', which postulated an advanced society characterised by '[V]igorous accelerating circulation, particularly the economic and pleasure-oriented, but other 
varieties as well'. There is now a considerable literature examining various forms of temporary mobility in developed world settings.

In Australia, as elsewhere, temporary movements are undertaken in response to a range of demographic, social, economic and environmental stimuli, and are facilitated by transport technology (Figure 1). Movements are conveniently classified according to whether they are undertaken for purposes of production or consumption at the destination (Williams and Hall 2000). Production-related moves are exemplified by fly-in fly-out/ drive-in drive-out mobility in the resources sector, long-distance commuting, seasonal agricultural mobility along with short-term business trips. Consumption-related mobility includes short-term tourist stays, visits to second homes, the extended cross-continental sojourns of elderly grey nomads, mobility to access health care, the mobility of indigenous peoples to participate in customary activities and visits to friends and relatives (Bell and Ward 2000). Critically, these different forms of mobility have distinct spatial and temporal signatures, the interaction of which underpin the short-term fluctuation in temporary populations stocks.

Bell (2004) identified nine dimensions of temporary mobility that vary for different movement types. These are movement intensity, spatial impact, connectivity, movement distance, spatial circuits, duration, seasonality, frequency, and periodicity. Table 1 illustrates variation in these nine dimensions for eleven types of mobility that are nationally or locally significant in Australia (Bell 2001; Charles-Edwards et al. 2008). We now describe these in turn.

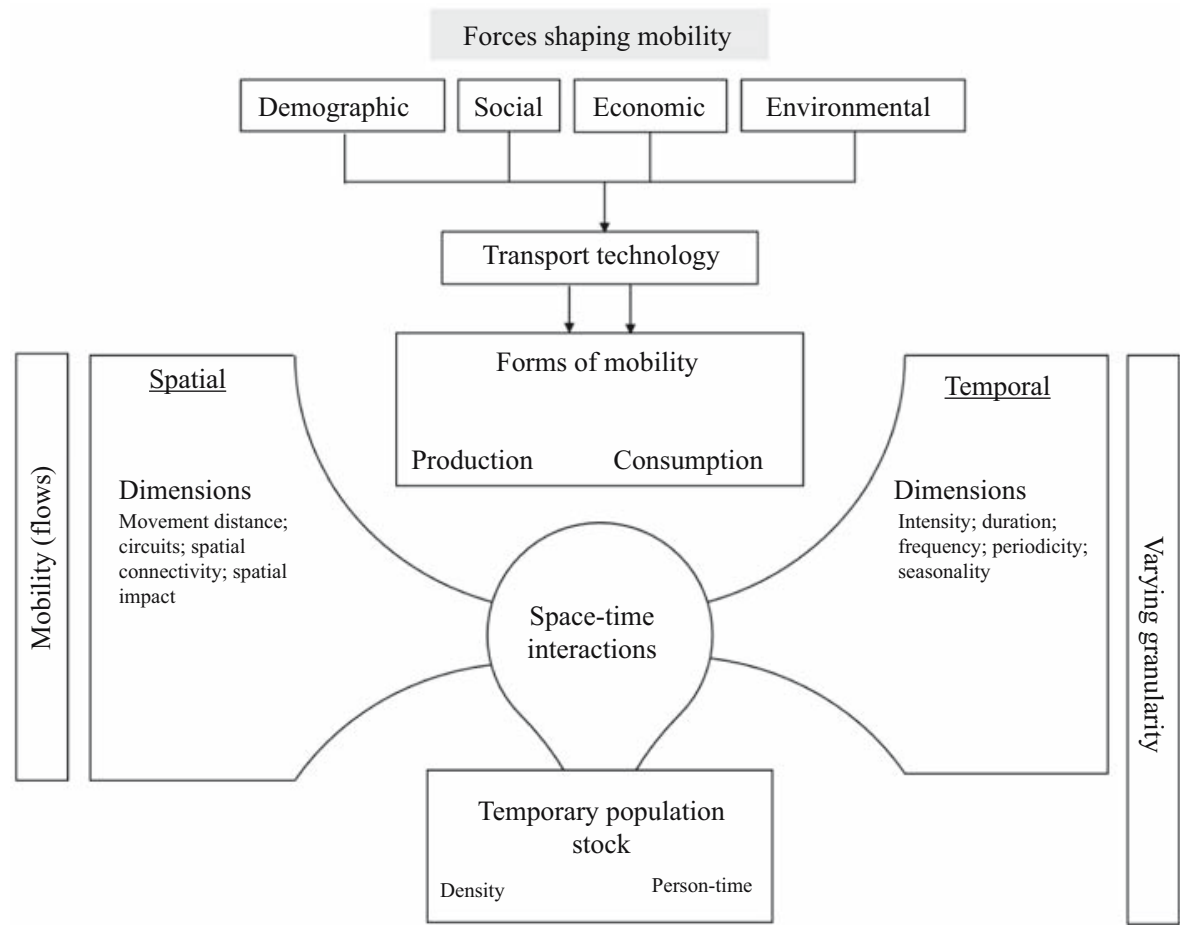

Fig. 1. Conceptualising the mobility system. 


\begin{tabular}{|c|c|c|c|c|c|c|c|c|c|c|c|c|c|}
\hline & & $\begin{array}{l}3 \\
: 0 \\
0 \\
.0 \\
0 \\
0\end{array}$ & 艿 & 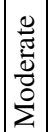 & 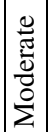 & 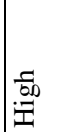 & 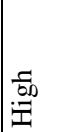 & $\begin{array}{l}\sqrt[5]{500} \\
\exists\end{array}$ & 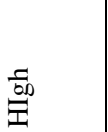 & $\mid \begin{array}{l}3 \\
0 \\
1 \\
1\end{array}$ & $\begin{array}{l}\text { 50 } \\
\text { :00 }\end{array}$ & 萼 & \\
\hline & 7 & 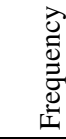 & 茎 & 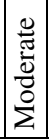 & $\begin{array}{l}\overrightarrow{5} \\
\stackrel{.00}{ \pm}\end{array}$ & 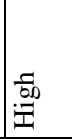 & \begin{tabular}{|l}
50 \\
哥
\end{tabular} & 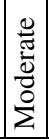 & $\begin{array}{l}\sqrt{50} \\
.1 \\
\end{array}$ & $\begin{array}{l}3 \\
0 \\
0 \\
0\end{array}$ & \begin{tabular}{|l}
50 \\
$\vdots$ \\
00
\end{tabular} & 咅 & $\begin{array}{l}50 \\
100 \\
1\end{array}$ \\
\hline & $\sum_{\text {至 }}^{E}$ & 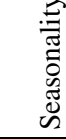 & 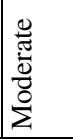 & 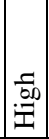 & $\begin{array}{l}3 \\
0 \\
0 \\
\end{array}$ & $\mid \begin{array}{l}\frac{0}{\pi} \\
\frac{\pi}{0} \\
\frac{\pi}{0} \\
\Sigma \\
\Sigma\end{array}$ & 茎 & 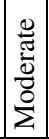 & 艿 & $\begin{array}{l}\tilde{5} \\
.00 \\
.9\end{array}$ & $\begin{array}{l}3 \\
0 \\
0 \\
\end{array}$ & 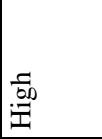 & \\
\hline$\underline{\underline{E}}$ & & 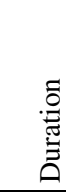 & 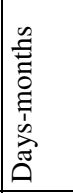 & 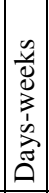 & 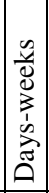 & 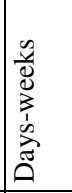 & 㐫 & 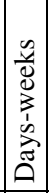 & $\begin{array}{l}\frac{n}{0} \\
\frac{0}{3} \\
\end{array}$ & 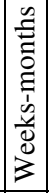 & 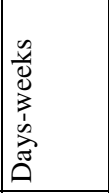 & 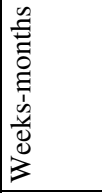 & 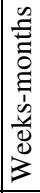 \\
\hline 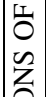 & & 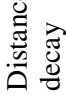 & \begin{tabular}{|l}
3 \\
0 \\
0 \\
1
\end{tabular} & 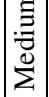 & $\mid \begin{array}{l}3 \\
0 \\
0 \\
1\end{array}$ & $\mid \begin{array}{l}3 \\
0 \\
0 \\
\end{array}$ & $\mid \begin{array}{c}50 \\
.00 \\
.0\end{array}$ & $\left|\begin{array}{c}5 \\
.50 \\
i]\end{array}\right|$ & 艿 & $\mid \begin{array}{l}3 \\
0 \\
0 \\
1\end{array}$ & $\begin{array}{l}3 \\
0 \\
0 \\
1\end{array}$ & 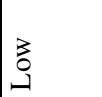 & $\mid$ \\
\hline 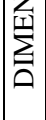 & & 莺 & 㐫 & $\mid \begin{array}{c}\frac{a}{a} \\
\stackrel{a}{a} \\
\text { is }\end{array}$ & 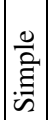 & 峁 & 竞 & 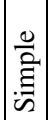 & 冚 & 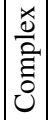 & 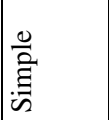 & 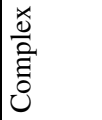 & \\
\hline & 导 & 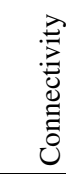 & 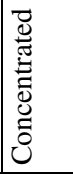 & 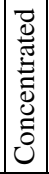 & 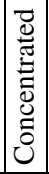 & 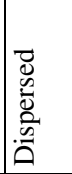 & 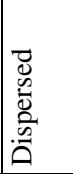 & 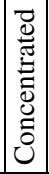 & 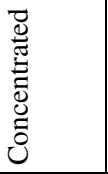 & 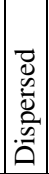 & 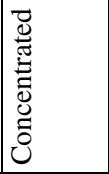 & 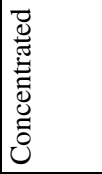 & 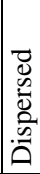 \\
\hline & & 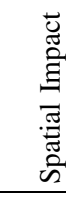 & 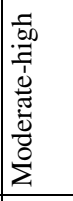 & 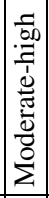 & $\mid \begin{array}{l}3 \\
0 \\
0 \\
\end{array}$ & 萼 & $\begin{array}{l}3 \\
0 \\
9 \\
\end{array}$ & 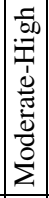 & $\begin{array}{l}\text {.50 } \\
\text { in }\end{array}$ & 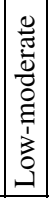 & ב⿱ & 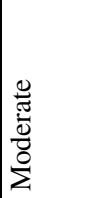 & 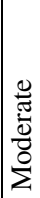 \\
\hline & & 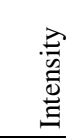 & 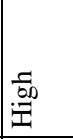 & 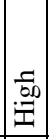 & $\begin{array}{l}\tilde{50} \\
.00\end{array}$ & 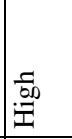 & 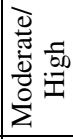 & 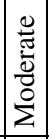 & 艿 & \begin{tabular}{|l}
3 \\
0 \\
-1 \\
\end{tabular} & 茎 & $\begin{array}{l}3 \\
0 \\
0 \\
\end{array}$ & \begin{tabular}{|l}
3 \\
0 \\
0 \\
\end{tabular} \\
\hline & & 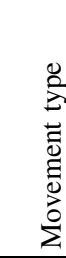 & 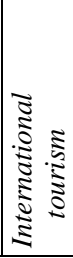 & 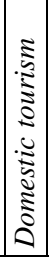 & 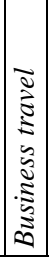 & 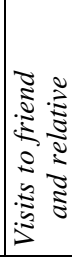 & 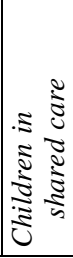 & 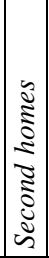 & 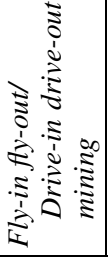 & 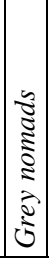 & 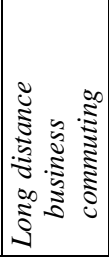 & 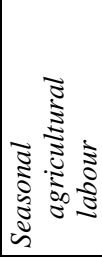 & 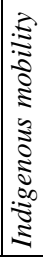 \\
\hline
\end{tabular}


Intensity refers to the overall level of movement within a population. This dimension allows numerically significant forms of mobility to be identified and also provides insights into the composition of temporary mobility in Australia. While data are incomplete, available information suggests that tourism, both international and domestic, business travel, and visits to friends and relatives have the highest intensity of temporary mobility in Australia (Charles-Edwards and Bell 2015). In 2018, there were more than 8.1 million short-term international visitors arrivals visiting for holidays, to see friends and relatives, on business, and for conferences or conventions (ABS 2019) and an estimated 42 million domestic tourism trips, 23 million business trips, and 33 million trips to visit friends and relatives taken by Australians aged 15 and older in the year ending September 2018 (Tourism Research Australia 2018). A distinct form of mobility tied to family is that of children in shared care arrangements following parental separation. One in five Australian children will experience parental separation before the age of 17 (Halford 2018), with 49\% of children staying overnight with their non-resident parent in 2012-2013 (ABS 2015). Other forms of mobility are locally important. Mobility tied to second homes is significant in several coastal areas, with second homes accounting for up to $50 \%$ of the housing stock (Paris et al. 2014). Fly-in fly-out and drive-in drive-out mining, whereby workers in the resource sector live remotely and travel to the mine site for extended shifts (two weeks onsite, one week off, for example), are a significant component of the population in resource regions, such as the Bowen Basin coal mining region of Queensland (QGSO 2018) or Western Australia's remote north-west (Houghton 1993). Other forms of longdistance commuting, for instance travel between regions and cities on a weekly basis, also occur, but there are no reliable statistics on the intensity of these movements. Grey nomads, older people who travel the country in recreational vehicles, are estimated at $2 \%$ of the Australian population (Davis 2011) and concentrate in northern Australia during the winter months. Other forms of mobility, such as seasonal agricultural mobility undertaken by international working holidaymakers and itinerant groups, are an important component of the workforce in many rural areas (Hanson and Bell 2007). Indigenous mobility is another significant form of movement, with extensive circuits of movement tied to customary activity and access to services across remote and rural Australia (Taylor and Bell 2012).

The demographic impact of temporary population mobility is determined by its intensity, but also by the degree to which temporary population mobility redistributes population across the settlement system or its spatial impact. Borrowing from conventional measures of permanent migration, this can be captured by measures of movement effectiveness, that is, the degree to which flows from one area to another are balanced by counter-flows in the opposite direction. A system with unidirectional flows will be highly effective at redistributing populations, while systems with balanced flows will result in minimal redistribution of the population, even though there may be a high intensity of movement. Although there is substantial evidence demonstrating the spatial concentrations generated by particular types of temporary mobility (see, for example Bell and Ward 1998), little work has been undertaken to directly measure movement effectiveness among temporary populations. That said, some assessment of particular types of movement can be made a priori. For example, seasonal agricultural labour, fly-in fly-out or drive-in drive-out mining are likely to be highly effective at redistributing 
populations due to the spatial concentration of the activities that trigger these moves. By contrast, business travel and visits to friends and relatives tend to more closely reflect national settlement patterns and are more likely to be balanced by counter-flows.

Another spatial aspect is connectivity, also termed spatial focusing (Plane and Mulligan 1997). In any system of interregional mobility, the magnitude of flows varies between origin and destination pairs. This reflects both the size of the populations at origins and destinations along with the distance between them, and also indicates the strength of functional linkages (Bell et al. 2002). While empirical evidence is scant, a high degree of spatial focusing at destinations is likely when mobility is triggered to access spatially concentrated goods or services. Second home mobility, for example, is concentrated in high amenity areas, often within a few hours of major population centres (Back and Marjavaara 2017).

With respect to movement distance, temporary movements in Australia involve longer distances on average than permanent migration (Bell and Brown 2006); however, the rate of distance decay varies according to the purpose of the move. Tourism movements (McKercher 2018) and second home mobility (Müller et al. 2004), exhibit high distance decay, whereas visits to friends and relatives and fly-in fly-out mining are less affected. Distance can also be a driver of temporary mobility. For example, mobility associated with fly-in fly-out/ drive-in drive-out mining substitutes for permanent moves in remote regions, where the costs of establishing permanent settlements are prohibitive (Houghton 1993).

The final spatial dimension of mobility concerns movement circuits. While some forms of mobility involve a simple oscillation between a single origin and destination (e.g., travel to and from second homes), others involve complex itineraries linking multiple destinations (Bell 2001). The mobility of seasonal agricultural workers is one such example, with working holiday makers, retirees and permanent itinerants following a series of harvest trails to meet seasonal demand for horticultural labour across regional Australia (Hanson and Bell 2007).

Shifting to the temporal dimensions of mobility, temporary movements are of variable duration, ranging from a single night (i.e., business travel) to sojourns extending over many months (i.e., grey nomads). Duration can be measured with respect to the length of absence from an origin, or the length of a visit at the destination. The majority of movements undertaken in Australia are of short duration, with around half of all movements undertaken within Australia being fewer than two nights in duration. Longer trips, however, make-up three-quarters of all nights away from home (Tourism Research Australia 2018), and thus have a disproportionate impact on temporary population stocks at origins and destinations.

Seasonality is a key aspect of mobility that differentiates it from permanent migration. Institutional seasonality, which reflects the timing of school and public holidays and religious festivals, such as Easter and Christmas, impact the timing of both discretionary tourism and business flows. Natural seasonality, driven by climatic factors, is evident in the mobility of tourists, grey nomads and seasonal agricultural labour. The areal expanse of Australia, spanning multiple climatic zones, produces a north-south gradient in seasonality. Visits peak in the north of the country during the southern hemisphere winter, or "dry season", at which time climate is comfortable and roads are accessible. By 
contrast, visits in southern Australia peak over the summer months (Charles-Edwards and Bell 2015). Seasonality means that the timing of peaks in temporary populations varies across the country.

The frequency of mobility refers to the number of moves undertaken by a person in a fixed interval. Some forms of mobility are undertaken at frequent intervals, such as the movements associated with long-distance business commuting or second home ownership. Other movements are more sporadic, for example, occasional tourist trips. Like a number of other dimensions of mobility, frequency can be measured with respect to absences from an origin, and may involve multiple destinations for different purposes, or may reflect frequent visits to a particular destination. Movement frequency can have implications for estimates of temporary populations, as it leads to a divergence between the number of moves and the number of movers as the measurement interval increases. Data from the Australian National Visitor Survey reveal that one quarter of Australians aged 15 and over make an overnight trip in any given four week period. Of these, only $77 \%$ make a single trip, but $45 \%$ of trips are made by repeat movers (Tourism Research Australia 2018). This suggests that repeat movers account for a disproportionate share of temporary populations.

Periodicity combines information on frequency and duration to capture the sequences of movements (Taylor and Bell 2012). Fly-in fly-out mobility, mobility tied to second homes and many forms of customary mobility undertaken by indigenous Australians can all demonstrate a high degree of periodicity that differentiates them from other forms of mobility of similar duration. Periodicity may be of interest to planners and policy makers as it can impact the level of place attachment and different service requirements of visitors at destinations, with regular visitors having different demands to those visiting a region on a one-off basis.

The nine dimensions of mobility proposed by Bell (2004) highlight the complex spatiotemporal behaviours that characterise temporary forms of mobility in Australia. Useful progress has been made in developing robust measures that capture these multiple dimensions of mobility (see, for example Charles-Edwards and Bell 2015; Taylor and Bell 2012), but implementation is commonly hampered by a lack of consistent, reliable data. Moreover, even the more straightforward metrics, such as intensity and duration, depend on whether the movement is measured at the origin or destination. Equally challenging is whether to measure moves or movers, more or less identical when the observation interval is short, but divergent as the interval lengthens due to repeat mobility. The dimensions described above provide important insights into the dynamics of mobility, and the processes that generate shifts in the population surface from day to day, week to week and month to month, but they are not necessarily the measures that are best suited to the needs of users, nor are they readily estimated by statistical agencies.

\section{Survey of User Needs}

An understanding of user needs is fundamental to the production of official statistics (Raymer et al. 2015). While there have been long-standing calls for the estimation of temporary populations (Smith 1989; Cook 1996, 1998; Hugo and Harris 2013), little is known about user requirements with respect to population coverage, geography, the 
frequency of estimates, population characteristics and the types of metrics that may be of most use. To gain insight into user needs, an online survey was distributed with support from the Australian Bureau of Statistics to a range of stakeholders including government agencies, state statistical offices, local government associations and the private sector. The survey was initially distributed to a list of over 100 individuals and organisations, with users encouraged to share the survey link with others in their network. A total of 57 responses were received. Most respondents worked in the government sector, with 25 employed in local government, and a further 26 in state or federal agencies. Four respondents were private sector employees, while one was employed in academia. One respondent did not state their employment sector. The survey asked fifteen questions relating to the potential uses of temporary population estimates, desired population coverage, the temporal resolution of estimates, the output geography and population characteristics of interest. We note that the sample is largely comprised of local government planners and officials and recognise that other users may have different needs.

\subsection{Why are Estimates of Temporary Populations Needed?}

Fundamental to the creation of official statistics is an understanding of the need for, and utility of, any output statistics. Respondents were asked an open-ended question on the need for estimates of temporary populations. All respondents (57) answered this question. Responses were manually coded using an inductive approach. Codes were first created based on a $50 \%$ sample of responses. These codes were then reapplied to this sample to validate before being applied to the remaining responses. Results are shown in Figure 2. The major application of temporary population estimates was seen to lie in better planning and provision of local goods and services (36 of 57 responses) to cater for peak and seasonal variations in demand. A second commonly cited purpose was to provide a more robust basis for the equitable distribution of Commonwealth Government financial resources to local government authorities (10/57). These are currently allocated using a formula based principally on de jure population estimates prepared by the Australian

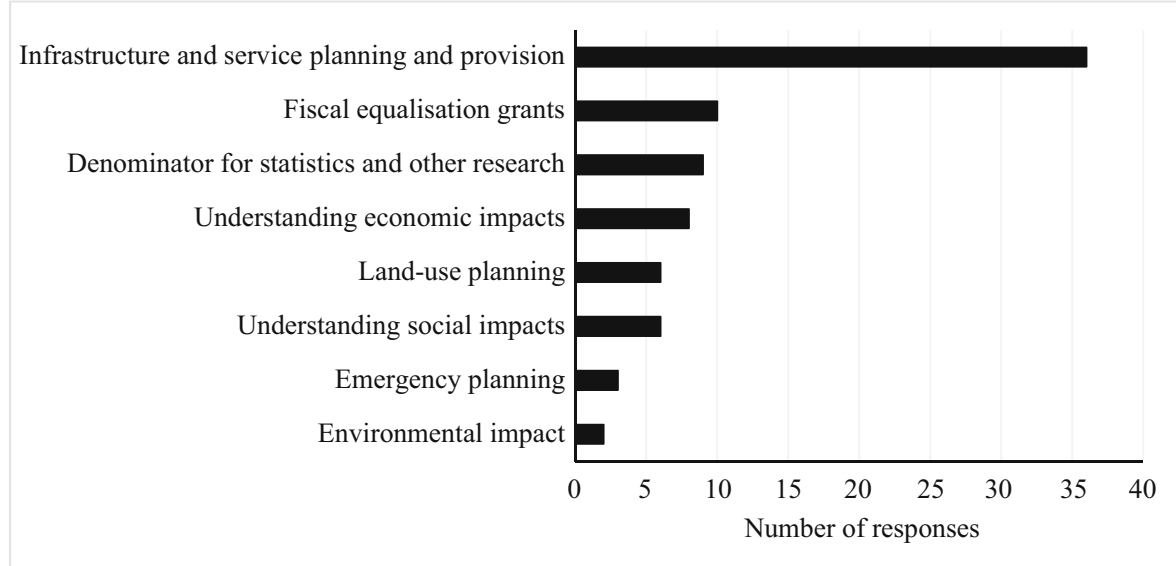

Fig. 2. Need for estimates. 
Bureau of Statistics, which are seen as disadvantaging local authorities that host large temporary populations.

Other responses included the need for appropriate denominators for crime and health statistics, a theme that has emerged in the academic literature, as well as information to better understand the nature of the temporary populations themselves (e.g., fly-in-fly-out populations). A number of respondents suggested that estimates were needed to better understand the economic (8/57), social (6/57) and environmental impacts (2/57) of temporary populations. This included the need for statistics to better model labour market impacts and local economic effects, including the impact of temporary population on housing affordability arising from the short-term letting market. Land-use planning, particularly as it relates to land supply, and emergency planning and preparedness, were also nominated. The results overwhelmingly focused on local impacts, perhaps unsurprising given the high proportion of local government officials among respondents, but there was also a desire for statistics with wider geographic coverage for modelling and research purposes.

\subsection{Who Should be Captured?}

Respondents were asked to identify the groups of visitors that are significant in their region of interest from a closed list, with multiple responses accepted (Figure 3). Domestic tourists (48/57) and international tourists (44/57) topped the list, reflecting the high overall intensity of these movements. Second home owners (36/57) were also of strong interest, followed by grey nomads (33/57), fly-in fly-out (30/57) and drive-in drive-out workers (29/57). Indigenous peoples, seasonal and itinerant workers, homeless populations, people visiting friends and relatives, and international workers received fewer mentions. Two respondents noted that a single index capturing all forms of temporary population, irrespective of motives, would be most valuable.

In addition to information on overnight visitors, respondents expressed a need for estimates of daytime populations, including commuters (28/57) and those travelling for

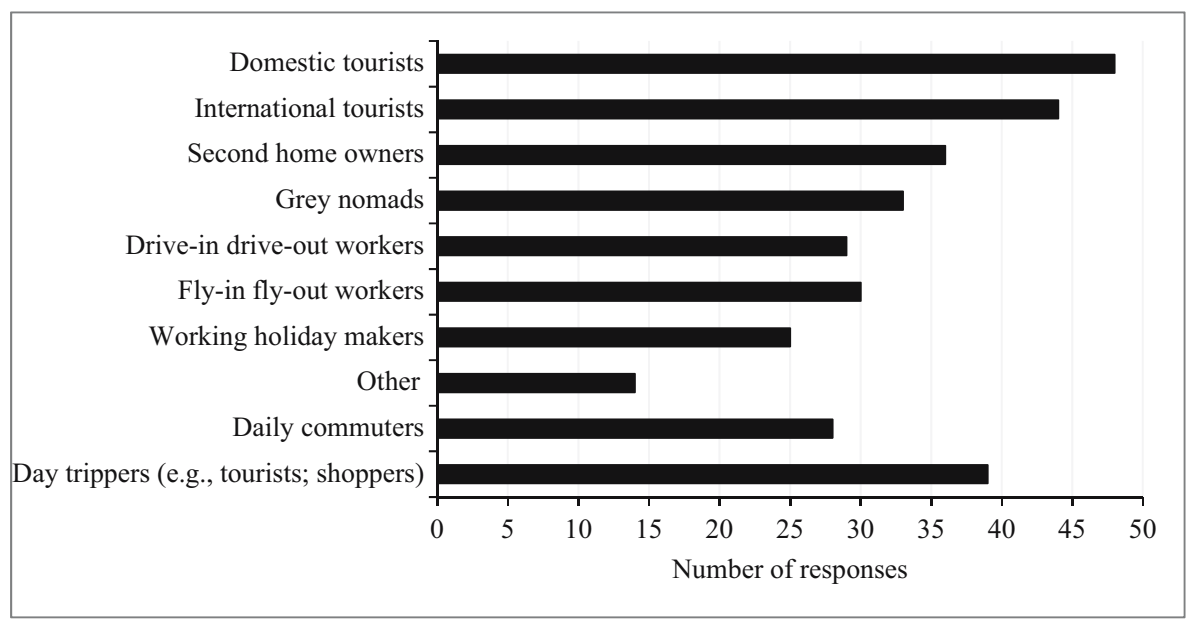

Fig. 3. Types of visitors. 
consumption-related purposes (39/57). Most of these preferred separate estimates of daytime as against overnight populations (38/55). Respondents were also asked about the need to identify the purpose of the move. A total of 47 of 57 respondents wanted to distinguish tourists, while 46 wanted to separately identify business travellers. Thirty-eight respondents wanted to know if visitors accessed goods and services at the destination and 45 thought it was important to distinguish between occasional and repeat visitors (e.g., second home owners). What emerges from these results is the diverse composition of temporary populations across Australian regions. For official statistical purposes, targeting population subgroups for estimation may produce locally useful results, but will not serve as a national standard.

\subsection{Temporal Framework}

A key feature of temporary populations is their variation over time, therefore a single point estimate is unlikely to adequately represent the temporary population of an area. Respondents were asked about the temporal variations in populations they were most interested in capturing from a closed set of responses (Figure 4). Seasonal variation in population numbers was the most common response (49/56), followed by variations between weekday and weekend populations (35/56). Estimates capturing holiday populations were nominated by 34 respondents. Daily estimates were nominated by 16 . Significantly, there was little desire for estimates capturing variation over the course of a single day (12/56). Other time periods were nominated by 13 respondents; these included estimates capturing monthly variations (3), periods coincident with

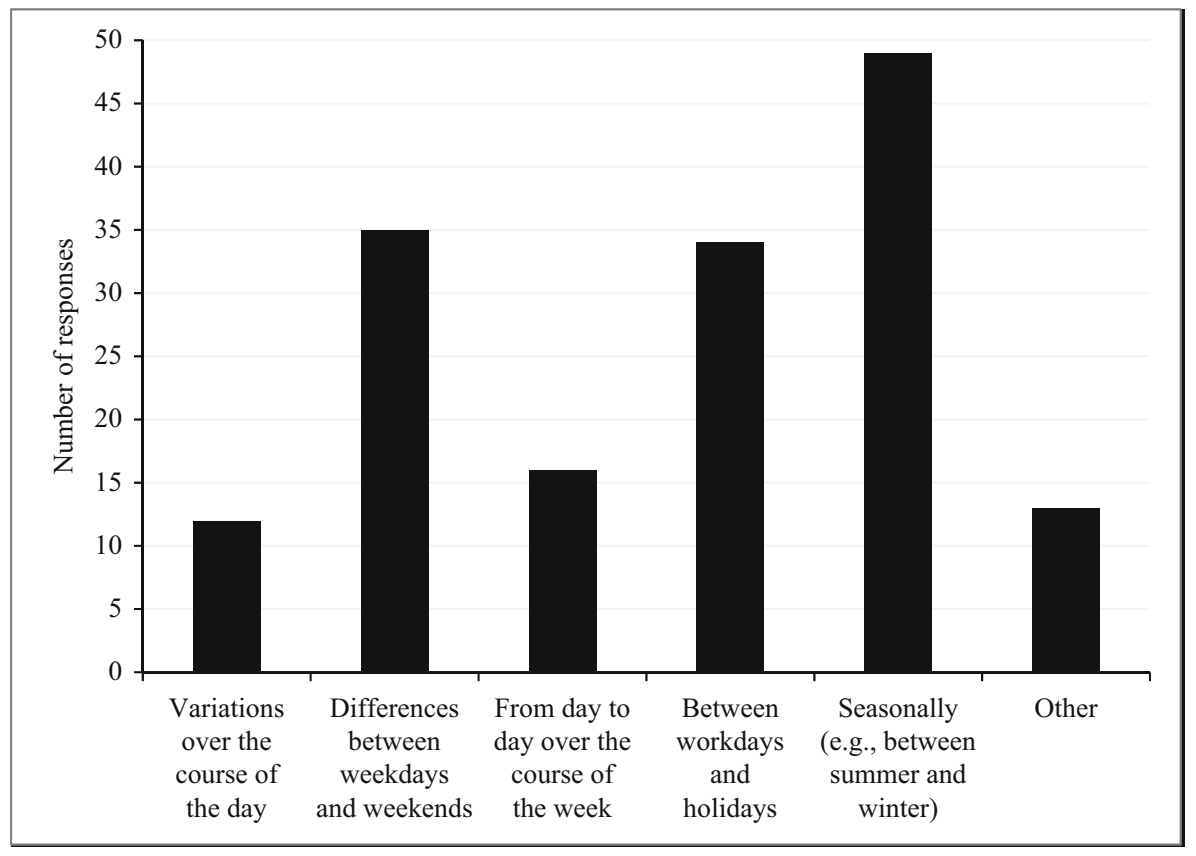

Fig. 4. Temporal variation to be captured. 
agricultural harvest seasons (2), estimates timed to capture specific events (2), and single point estimates to facilitate comparison with other Australian population statistics. The results suggest that daily estimates would best meet the needs of most users; however, the data and processing needed for continuous estimates are significant. Monthly estimates offer a potential compromise providing a balance between temporal specificity and data demands.

\subsection{Geography}

Respondents were asked about the geographic scale at which estimates were needed. Results are summarised in Figure 5, differentiating three levels in the hierarchy of spatial units that make up Australia's regional statistical framework: States and territories (of which there are nine), Local Government Areas (LGAs - 563), and Statistical Areas Level 2 (SA2s - 2310). Local Government Areas (44/57) emerged as the spatial unit for which such estimates were most widely sought, unsurprisingly given that local government officials comprised almost half the respondents. However, a large proportion of respondents underlined the need for estimates at the small area level. SA2s, a geographic unit with an average population of around 10,000 people (ABS 2016), were nominated by 42 respondents. Other responses requested estimates for individual towns, suburbs and discrete communities, as well as for Level 1 Statistical Areas, which have an average population of just 400 people. At the other end of the spatial scale, States and territories were nominated by nine respondents, while others pointed to a need for custom geographies, included gridded population data. The results confirm that estimates are needed at relatively high spatial resolution, and also reveal a desire to aggregate estimates over space. Estimates must therefore be in a form that allows summation over multiple spatial units without risking double counting of populations.

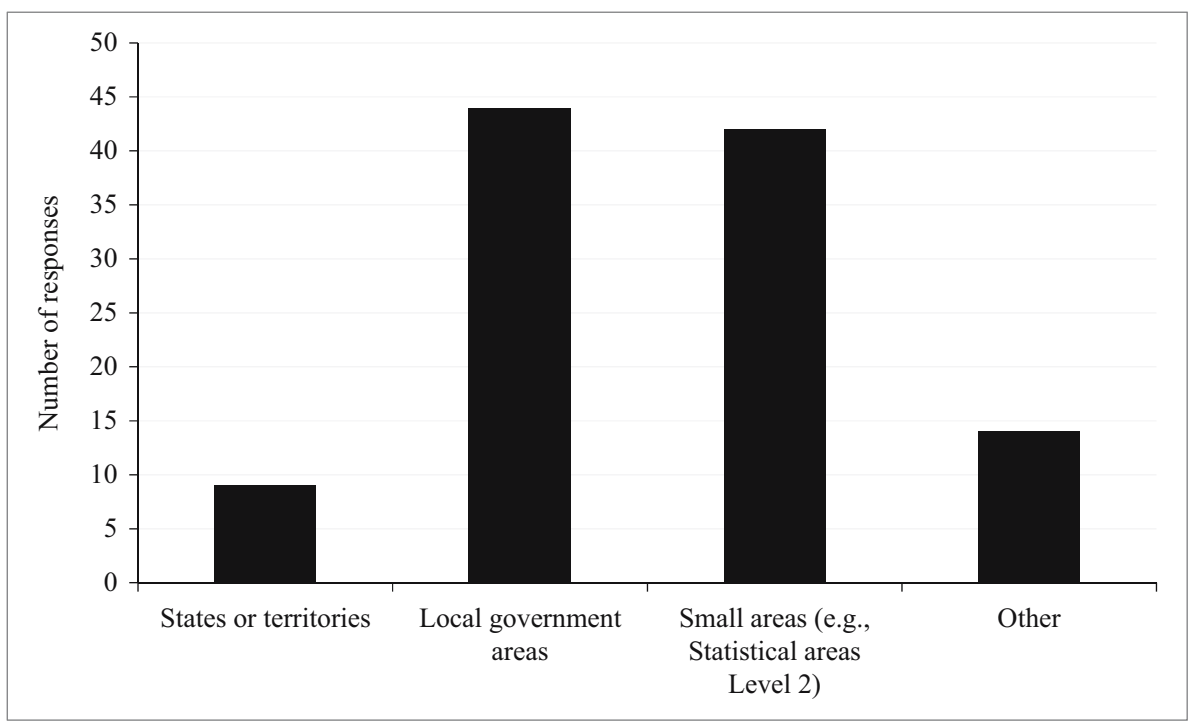

Fig. 5. Australian geographic units for which respondents sought estimates of temporary populations. 


\subsection{Measures}

To gain a better understanding of the most useful output statistic, four measures of temporary populations that commonly appear in the literature as options were put to respondents (see Figure 6). These were:

1. The peak visitor population;

2. The total number of visitors in some period (e.g., a week, month or year);

3. The population present at a defined point in time; and

4. Visitor nights (or Person-time).

Estimates of the peak visitor population were the most popular option in the survey, nominated by 42 of 57 respondents. There are two ways in which measures of peak visitor populations are commonly implemented. The first is a measure of the capacity of an area, that is, the maximum number of people that can be accommodated in private and commercial accommodation (Planning Information and Forecasting Unit 2006). Estimates of capacity can be derived from tourist accommodation surveys, counts of unoccupied or second dwellings (McKenzie and Canterford 2018), or employer-provided housing, such as mining camps, as well as data from sources such as (AirDNA 2019). The second approach is to estimate the peak in actual visitor numbers, either directly from survey data or indirectly using symptomatic data (Smith 1989) to model the change in population numbers over time, benchmarked against the usually resident population. Examples include the use of wastewater data (SGS Economics and Planning 2007), retail spending statistics (Smith 1994), and mobile phone activity (Edmondson et al. n.d.). There are limitations to both the capacity approach and measures of the actual peak in population numbers. Estimates of capacity do not capture the timing of visits, and when aggregated over multiple spatial units, will produce a figure many times larger than the population, actually present. By contrast, it may be possible to capture the timing of population peaks, but again, estimates cannot be aggregated because the seasonality of temporary movements varies widely across space.

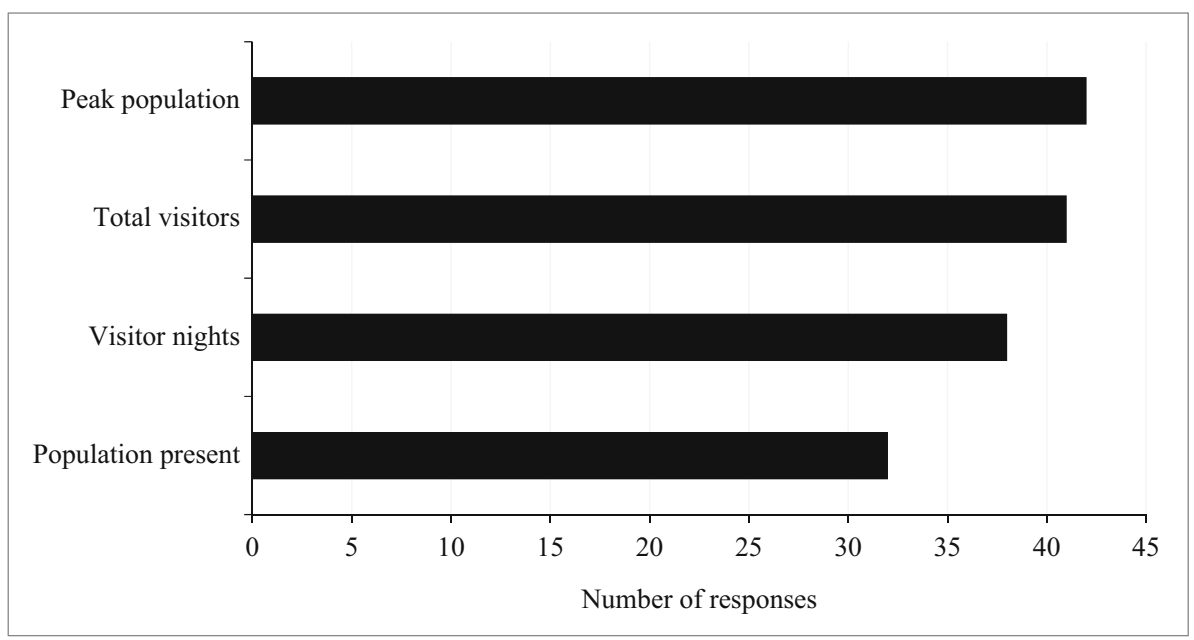

Fig. 6. Potential measures of temporary populations. 
Forty-one respondents nominated estimates of the visitor population in a defined interval, such as a month or a year, as a statistic of interest. This measure corresponds closely to the concept of a service population, that is, the population that accesses goods and services in a defined area (ABS 2008; United Nations 2017). In practice, visitor population estimates tend to capture specific groups, such as elderly snowbirds, who migrate seasonally from northern to southern states of the United States over the winter months (Happel and Hogan 2002) or indigenous populations (Markham et al. 2013). Such estimates undoubtedly provide insights into the demand for some goods and services and visitor characteristics, but rarely reflect the actual population in a region at a given point in time. Efforts to estimate total visitor numbers by summing the component visitor groups (e.g., tourists + business travellers + commuters) risk double-counting individuals belonging to multiple populations (StatsNZ 2015). Double-counting is also an issue if estimates are for large areas, as movers can be counted at both their origin (as a resident) and the destination, or at multiple destinations if a trip involves a complex circuit. These issues are compounded if estimates are summed across multiple geographical units.

A third option put to respondents was a measure of visitor nights or person-time spent in a region, which was nominated by 38 of 57 respondents. Visitor nights is a common metric in tourism research (Theobold 2005), while person-time is a concept familiar to demographers and epidemiologists (Vandenbroucke and Pearce 2012), used in the calculation of occurrence-exposure rates. In essence, person-time combines information on the number of visitors (and absentees) in a region with the duration of time they spend in that region. In contrast to instantaneous estimates of the population present, person-time measures capture population over extended discrete time intervals that can be of varying duration. Persontime is not impacted by double-counting and can be aggregated over both space and time. Also, person-time can be used to approximate the average population present in a region in a defined interval by dividing the total person-time by the number of time units in the interval. However, it has not been widely adopted in the literature as a measure of temporary population (for exceptions, see Smith 1989; Batista e Silva et al. 2017).

Population present at a defined point in time was nominated by 32 of 57 respondents as a useful measure of temporary populations. Estimates of the temporary population present capture the number of people in an area at a given point in time and are conceptually equivalent to a de facto population figure. The latter would include both usual residents and visitors to a region. Given the significant seasonal variation of many forms of temporary movement, frequent estimates would be needed to capture peaks and troughs in population numbers. Population present measures have been generated using symptomatic data, including mobile phone data, to track changes in populations over time (Deville et al. 2014). An alternative approach is to estimate the various components of the population at a set point in time (see Swanson and Tayman 2011, for a formulation of this concept). However, in the absence of temporally and spatially synchronised data enumerating different groups, double counting is a potential source of error. Population present estimates have many merits. They are conceptually consistent with de facto population statistics and are not susceptible to double counting, as movers must be physically present in a region to be counted. Population present estimates can be aggregated across multiple geographies, though not over time. If estimates are produced at high frequency, summary metrics, such as the peak and average population of a region, can also be created. 


\subsection{Other Characteristics}

Respondents were asked what was needed in regard to the characteristics of temporary movers. Age was seen as important by 48 of 54 respondents, while sex was nominated by 29 . Other characteristics mentioned by respondents included indigenous status $(6 / 54)$ and employment status (5/54). Given the difficulties in capturing population totals, at this time, estimates of other characteristics are a secondary concern, although information on age and sex would have clear value.

Synthesising the results of the survey, some principles for temporary population statistics can be identified. Population outputs need to include all visitors to a region, including domestic and international visitors, and occasional and regular visitors. The highest demand is for estimates that capture seasonal variation in population numbers and for small geographic areas. In Australia, Local Government Areas were nominated as the preferred spatial unit, reflecting their political function, but Statistical Areas, Level 2, with an average population across the country of around 10,000 persons (ABS 2016), and bespoke geographies were also identified as necessary. Fine spatial units would facilitate user wishes for estimates that can be aggregated into custom regions. Concerning the type of measure, respondents sought a wide range of statistics, including the ability to differentiate seasonal and periodic change. Within that framework, they also called for measures covering various aspects, including the peak population, total visitors and visitor nights. They also wanted information on characteristics and motives, but these emerge as secondary priorities. While this does not provide definitive guidance, it does demonstrate that demand is high and that all forms of data would likely be well received. In the first instance, at least, the way forward therefore, should be guided by considerations of data availability and processing.

\section{Official Temporary Population Statistics: A Survey of OECD Countries}

Temporary population statistics do not generally form part of standard national statistical outputs. However, a range of information is captured in other collections that may serve as input into temporary population estimates. These include travel and tourism surveys that capture information on domestic and international travel. Questions on temporary populations have been asked in a number of national censuses. For example, the 2011 Census of England and Wales asked "Do you stay at another address for more than 30 days a year?". A number of countries record information on second homes, but information must be accompanied by data on utilisation to produce population estimates (Back and Marjavaara 2017). In recent years, several statistical agencies have also explored the utility of mobile phone and other "big data" sets as a source of information on population mobility, with pioneering work in this space emerging in Estonia (Ahas et al. 2011). To take stock of progress, we undertook a desktop survey of the national statistical agencies of 35 OECD member countries to determine the type of population estimates currently produced (de jure, de facto and working) and whether any type of temporary population estimates are available or undergoing development. We also sought to identify national travel and tourism surveys that collect data on temporary population mobility that may be used to inform official estimates. For this exercise, temporary population statistics were defined broadly as any statistic that counts a non-resident population; this includes both 
diurnal and overnight visitors. The review was undertaken in the last quarter of 2018 and was limited to national statistical agencies. Other government agencies, such as tourism bureaus or regional government offices might also produce relevant statistics, but these fell outside of our survey frame. As the survey was confined to online resources, results should be viewed as indicative rather than definitive, but do provide a flavour of contemporary approaches in the sample countries.

Results are shown in Table 2. Consistent with the UN Principles and Recommendations (United Nations 2017), all OECD countries produce de jure population estimates and most censuses are carried out on a de jure basis. However, five member countries also publish de facto counts from national population censuses (Australia, Ireland, Israel, Italy, and New Zealand). Comparison of de facto and de jure counts can provide useful insights into the overall intensity and spatial impacts of temporary mobility (Bell and Ward 2000). In the 2001 Australian Census, nearly 5\% of the Australian population were enumerated away from home in a distinctive spatial pattern. Cross-tabulating place of usual residence by place of enumeration also helps identify origin-destination flows among temporary

Table 2. Desktop survey of official population statistics, OECD members.

\begin{tabular}{|c|c|c|c|c|c|c|}
\hline Country & $\begin{array}{l}\text { De } \\
\text { jure }\end{array}$ & De facto & $\begin{array}{l}\text { Working } \\
\text { population } \\
\text { (from census } \\
\text { or register) }\end{array}$ & $\begin{array}{l}\text { Temporary } \\
\text { population } \\
\text { estimates }\end{array}$ & $\begin{array}{l}\text { Travel or } \\
\text { tourism } \\
\text { survey }\end{array}$ & Notes \\
\hline Australia & Yes & Yes & Yes & No & Yes & 1 \\
\hline Austria & Yes & No & Yes & No & Yes & \\
\hline Belgium & Yes & No & Yes & No & Yes & \\
\hline Canada & Yes & No & Yes & No & Yes & \\
\hline Chile & Yes & No & Yes & No & Yes & \\
\hline Czech Republic & Yes & Not known & Yes & No & Yes & \\
\hline Denmark & Yes & No & Yes & Yes & Yes & 2 \\
\hline Estonia & Yes & No & Yes & Yes & Yes & 3 \\
\hline Finland & Yes & No & Yes & No & Yes & \\
\hline France & Yes & No & Yes & Yes & Yes & 4 \\
\hline Germany & Yes & Not known & Not known & No & Yes & \\
\hline Greece & Yes & Not known & Not known & No & Not known & \\
\hline Hungary & Yes & Not known & Yes & No & Yes & \\
\hline Iceland & Yes & No & Not known & No & Yes & \\
\hline Ireland & Yes & Yes & Yes & Yes & Yes & 5 \\
\hline Israel & Yes & Yes & Yes & No & Yes & \\
\hline Italy & Yes & Yes & Yes & Yes & Yes & 6 \\
\hline Japan & Yes & No & Yes & No & Yes & \\
\hline $\begin{array}{l}\text { Korea } \\
\quad \text { (Republic of) }\end{array}$ & Yes & Not known & Not known & No & Not known & \\
\hline Latvia & Yes & No & Yes & No & Yes & \\
\hline Luxembourg & Yes & No & No & No & Yes & \\
\hline Mexico & Yes & Not known & Yes & No & Yes & \\
\hline Netherlands & Yes & No & Yes & Yes & Yes & 7 \\
\hline New Zealand & Yes & Yes & Yes & Yes & Yes & 8 \\
\hline Norway & Yes & No & Yes & No & Yes & \\
\hline Poland & Yes & No & Yes & No & Yes & \\
\hline Portugal & Yes & No & Yes & No & Yes & \\
\hline Slovak Republic & Yes & Not known & Yes & No & Yes & \\
\hline Slovenia & Yes & No & Yes & No & Yes & \\
\hline
\end{tabular}


Table 2. Continued.

\begin{tabular}{|c|c|c|c|c|c|c|}
\hline Country & $\begin{array}{l}\text { De } \\
\text { jure }\end{array}$ & De facto & $\begin{array}{l}\text { Working } \\
\text { population } \\
\text { (from census } \\
\text { or register) }\end{array}$ & $\begin{array}{l}\text { Temporary } \\
\text { population } \\
\text { estimates }\end{array}$ & $\begin{array}{l}\text { Travel or } \\
\text { tourism } \\
\text { survey }\end{array}$ & Notes \\
\hline Spain & Yes & No & Yes & No & Yes & \\
\hline Sweden & Yes & No & Yes & Yes & Yes & 9 \\
\hline Turkey & Yes & Not known & Not known & No & Yes & \\
\hline United Kingdom & Yes & No & Yes & Yes & Yes & 10 \\
\hline United States & Yes & Yes & Yes & No & Yes & \\
\hline
\end{tabular}

1. The Australian Bureau of Statistics conducted a pilot study to estimate temporary populations based on mobile phone data in 2016. The pilot study has yet to be released. http://www.abs.gov.au/websitedbs/ $\mathrm{d} 3310114 . n s f /$ home/ABS + Media + Statements +-+ Response + to + reports + about + use + of + aggregate + level + telco+data

2. Holiday dwellings: number and nights spent (https://www.dst.dk/en/Statistik/dokumentation/documentationofstatistics/holiday-dwellings)

3. Feasibility study on the use of mobile positioning data for tourism statistics (https://www.stat.ee/78262? highlight $=$ mobile\%2Cphone); Commuting in Estonia. An analysis based on mobile positioning data https:// www.stat.ee/65754?highlight $=$ mobile\%2Cphone

4. Daytime population (https://www.cso.ie/en/releasesandpublications/ep/p-cp11eoi/cp11eoi/dtpn/)

5. Population a compete a part: this captures people counted away from their commune of usual residence, but certain groups are excluded, for example military personnel, people in hospitals, people in convents/monasteries https://www.insee.fr/fr/metadonnees/definition/c1650

6. 2001 Census question on multiple residences (https://unstats.un.org/unsd/demographic/sources/census/quest/ ITA2001en.pdf)

7. Mobile phone estimates How many people are here? (https:/www.cbs.nl/en-gb/our-services/innovation/ project/how-many-people-here-)

8. Using mobile phone data to measure population movements (https://www.google.com/url? $\mathrm{sa}=\mathrm{t} \& \mathrm{rct}=$ $\mathrm{j} \& \mathrm{q}=\& \mathrm{esrc}=\mathrm{s} \&$ source $=$ web $\& \mathrm{~cd}=1 \& \mathrm{ved}=2 \mathrm{ahUKEwj}$ sweavzqjgAhXNfH0KHVUDBI0QFjAAegQIChAC \&url $=$ http $\% 3 \mathrm{~A} \% 2 \mathrm{~F} \% 2 \mathrm{Farchive}$.stats.govt.nz $\% 2 \mathrm{~F} \% 2 \mathrm{Fmedia} \% 2 \mathrm{FStatistics} \% 2 \mathrm{Fservices} \% 2 \mathrm{Fearthquake}-$ info\%2Fusing-cellphone-data-measure-pop-movement.pdf\&usg=AOvVaw1vjQVs2_SDGgvNrhlHNwlb)

9. Holiday home areas (https://www.scb.se/en/finding-statistics/statistics-by-subject-area/environment/land-use/ concentrations-of-holiday-homes/)

10. Workday population (https://www.ons.gov.uk/peoplepopulationandcommunity/populationandmigration/ populationestimates/articles/theworkdaypopulationofenglandandwales/2013-10-31); 2011 Census question on second address (https://www.ons.gov.uk/peoplepopulationandcommunity/housing/bulletins/2011censusnumber ofpeoplewithsecondaddressesinlocalauthoritiesinenglandandwales/2012-10-22)

movers, while other census questions also reveal their characteristics. However, these benefits of compositional and spatial detail are offset by the fact that the census provides a snapshot of temporary mobility on a single day of the year, which may not be more broadly representative. In the United States, the American Community Survey (ACS) captures a modified de facto population based on a current residence rule, interviewing people living at an address for more than two months. Official guidance suggests that the data produced by the ACS are similar to usual resident counts derived from the decennial Census, except in areas '. . . that include large beach, lake, or mountain vacation areas, or large migrant worker communities. .' (U.S. Census Bureau 2018, 60). In addition to de jure and de facto counts, estimates of working populations (i.e., based on place of work or study) are available from the Census or population registers in 28 countries.

Temporary populations statistics, defined in this instance to include daytime populations are produced in 9 of the 35 OECD member countries. Statistics fall into three main types. 
The first estimate daytime populations using a combination of working population and usual resident statistics captured by national censuses (see, for example the UK Office of National Statistics (ONS 2014) and the Irish Central Statistics Office (CSO 2017)). These estimates use an accounting framework in which entrants to the population are people working in a region, while exits are usual residents working outside the region. The statistical output is an estimate of the average population present in a region during working hours.

The second group of estimates capture second home populations using surveys (e.g., Denmark), administrative data (e.g., Sweden) or via a census (England and Wales, and Italy). These estimates have varying conceptual bases in different countries. In Sweden, statistics are produced measuring the number of second home dwellings, but not their associated population, in a defined area, which can be used to estimate carrying capacity. In Italy, and England and Wales, statistics capture the number of people who used a second dwelling in the year prior to the Census. In Denmark, estimates are produced of both the number of second homes and the cumulative person-nights spent in those homes.

The third group of estimates capture temporary populations using mobile phone data. Statistics Netherlands has produced experimental estimates of the population present in municipalities at hourly intervals (CBS n.d.). In Australia, mobile phone data have been explored for their use in population estimates (ABS 2018). In addition to instantaneous estimates of the population present, mobile phone data have been used to capture temporary population flows. In Estonia, commuting and tourist flows have been monitored in partnership with academic researchers (Ahas et al. 2011; Ilves and Karus 2014). Statistics New Zealand used mobile phone data to track the temporary movements of people following the Christchurch earthquake in 2011 (StatsNZ 2012).

The desktop review suggests that there is some interest in the production of temporary population statistics in OECD countries, but there is no consensus as to how these are best conceptualised or produced. Approaches vary with respect to population coverage (e.g., daytime populations, second home owners, all visitors), how estimates are conceptualised (e.g., person-time, population present) and the methods and data used to produce the estimates. However, almost all countries do conduct some form of tourism or travel survey that can provide data on common forms of temporary population mobility. While progress is needed on multiple fronts, clear conceptualisation of temporary population statistics is a critical first step.

\section{Towards Official Temporary Population Statistics}

To date, there has been little progress in the production of temporary population statistics. This is not due to a lack of demand, as calls for temporary population statistics go back decades. What can account for this lack of progress? A paucity of data and inadequate processing procedures are undoubtedly factors, as is the embryonic state of conceptualisation of temporary populations and poor understanding of the underlying dynamics of temporary mobility. "Service population" is the principal concept relating to temporary populations in the official statistical literature, having entered the lexicon of the United Nations Population Division, and national statistical agencies, including Statistics New Zealand and Australia (see, for example StatsNZ 2015; ABS 2008). This concept has proven difficult to implement across multiple geographies and multiple population groups, 
and suffers from a range of shortcomings associated with estimates of total visitors that are described in Subsection 3.5. Two concepts discussed in this paper may prove useful to progress temporary population estimates: population present and person-time. The strength of both measures is their ability to aggregate numbers across regions (and across time, in the case of person-time) and constrain them to national estimates. Daily population present estimates are consistent with demographic accounts, in that changes in population stocks can be linked to the flows driving dynamic shifts in populations (Rees and Wilson 1973). In practice, the implementation of a full set of multi-regional accounts at daily intervals is likely unworkable due to the complexity of the underlying temporary mobility that we have described in Section 3. However, high frequency estimates of the population present can be generated from symptomatic data for single areas, and for multiple geographies using mobile phone data (CBS n.d.).

While population present estimates are now feasible in some settings, data access remains a key impediment. Mobile phone records are available in some countries, but in others, privacy concerns, fragmentation across multiple providers, and cost make access difficult. Ironically, access to mobile phone data is often easier in developing world countries due to data philanthropy, particularly following natural disasters (Bengtsson et al. 2011; Wilson et al. 2016). Person-time estimates that combine information on the numbers of visitors (and absentees) in a region with the duration of time they spend in that region are an alternative. In contrast to population present estimates, person-time measures population over discrete time intervals that can be of varying duration. To estimate persontime, information is needed on both the intensity of movement and the duration of stay at a destination. Fortunately, such data are collected in travel and tourism surveys that are ubiquitous across OECD countries. These two options are not mutually exclusive. Persontime is consistent with instantaneous measures of population present: if the population present over time is represented by a curve on a population-time chart, person-time is equivalent to the area under the curve. This relationship between person-time and population present offers potential avenues for combining data from multiple sources. A framework that exploits this relationship provides flexibility across national contexts.

\section{Whither Temporary Population Estimates?}

In this article, we explored issues associated with the production of official temporary population statistics. Guided by the framework developed by Raymer and colleagues (2015) we touched on a number of interrelated elements: the dynamics of the mobility driving short-term shifts in population numbers in a developed world context, user needs for statistics on temporary populations, and existing outputs measuring temporary populations published by OECD countries. The culmination of the article was a discussion of two statistical concepts germane to temporary population statistics: estimates of population present and of person-time. These concepts are, of course, not new to demographers. Integrating under a curve of population counts to calculate person-time is key to the calculation of occurrence-exposure rates, as well as the $L_{x}$ column in life tables. However, these concepts have been absent from discussions of temporary population estimates. These concepts each have the potential to produce the statistics sought by users and the relationship between the two measures offers a potential avenue for combining 
data from different sources. Population present might be estimated using mobile phone data, while person-time might be derived from tourism surveys.

Statistical outputs are ultimately dependent upon matching concepts with available data sets. Temporary population mobility has not generally been measured in standard demographic collections, such as censuses or population registers. In instances where this has occurred (e.g., the 2011 Census of England and Wales), data have not been linked explicitly to clearly defined concepts. As data from mobile phone and other ICT develop, it is becoming more feasible to produce such estimates, but a number of challenges remain that relate to privacy, ownership, access and cost. There are also methodological and production challenges relating to bias, groundtruthing, and computing resource demands that are non-trivial (Tam and Clarke 2015), particularly if estimates are sought across multiple regions. In many instances, temporary population statistics will need to be based on a combination of disparate data sources, rather than a single data set. This echoes broader trends in the production of demographic statistics linking administrative data sets. Indeed, many countries are embarking on a transition away from traditional censuses, towards linked administrative data sets capable of producing longitudinal data (Kukutai et al. 2014). For example, Australia proposed replacing the 2016 Census with linked administrative data sets, although plans have since been put on hold (Bell 2015), while the Office of National Statistics (England and Wales) has a programme to develop an administrative census (ONS 2017). Systems are more developed in Nordic countries, with for example Statistics Finland having developed a fully operational statistical system linking population, business and property registers (Ruotsalainen 2018). The shift to longitudinal data offers promising new opportunities to assemble data on both suggested measures, first by providing an effective continuing census from which a snapshot of temporary populations can be extracted, and secondly by cumulating the time spent in particular jurisdictions to generate data on persontime. Also promising are longitudinal statistics on international visitors in countries such as Australia, which can be used to estimate the population physically present in a country by tracking arrivals and departures of international visitors and residents (Burleigh 2018). From this database, it is possible to estimate the persons present at any point in time, but person-time measures can also be generated by summing durations of absence and of stay. Despite these developments, longitudinal data are not essential for the production of person-time measures and their development should not lead agencies to overlook existing data sets, such as tourism and travel surveys that capture retrospective information on the intensity and duration of moves. Also useful are occupancy statistics collected in tourist accommodation surveys, and from online platforms, such as AirBNB and HomeAway (AirDNA 2019). The need for official temporary population statistics will ultimately vary across national contexts and will be impacted by data availability and processing capability. A clear and consistent conceptual approach is an important first step in the development of widespread temporary population statistics.

\section{References}

ABS. 2008. Information Paper: Population Concepts, 2008, Catalogue no. 3107.0.55.006. Canberra: Australian Bureau of Statistics. Available at: https://www.abs.gov.au/ ausstats/abs@.nsf/mf/3107.0.55.006 (accessed March 2019). 
ABS. 2015. Family Characteristics and Transitions, Australia, 2012-13, Catalogue no. 4442.0 Canberra: Australian Bureau of Statistics. Available at: https://www.abs. gov.au/ausstats/abs@.nsf/mf/4442.0 (accessed March 2019).

ABS. 2016. Australian Statistical Geography Standard (ASGS): Volume 1 - Main Structure and Greater Capital City Statistical Areas, Catalogue no. 1270.0.55.001. Canberra: Australian Bureau of Statistics. Available at: https://www.abs.gov. au/ausstats/abs@.nsf/mf/1270.0.55.001 (accessed March 2019).

ABS. 2018. Response to reports about use of aggregate level telco data. Canberra: Australian Bureau of Statistics. Available at: https://www.abs.gov.au/websitedbs/ $\mathrm{d} 3310114 . n s f / h o m e / A B S+$ Media + Statements +-+ Response + to + reports + about + use + of + aggregate+ level+ telco+data (accessed March 2019).

ABS. 2019. Overseas Arrivals and Departures, Australia, Dec 2018, Catalogue no. 3401.0. Canberra: Australian Bureau of Statistics. Available at: https://www.abs.gov. au/AUSSTATS/abs@.nsf/allprimarymainfeatures/A7FC8F595E0E1D63CA2583BD 0076FDF4?opendocument (accessed March 2019).

Ahas, R., S. Silm, A. Aasa, K. Leetmaa, E. Saluveer, and M. Tiru. 2011. "Commuting in Estonia. An analysis based on mobile positioning data." In Regional Development in Estonia, edited by E. Narusk, 197. Tallinn: Statistics Estonia. Available at: https://www. stat.ee/publication-download-pdf?publication_id=25596 (accessed May 2019).

AirDNA. 2019. "MarketMinder." Available at: https://www.airdna.co/vacation-rentaldata (accessed June 2019).

Back, A. and R. Marjavaara. 2017. "Mapping an invisible population: the uneven geography of second-home tourism." Tourism Geographies 19(4): 595-611. DOI: https://doi.org/10.1080/14616688.2017.1331260.

Batista e Silva, F., K. Rosina, M. Schiavina, M. Marin, S. Freire, M. Craglia, and C. Lavalle. 2017. Spatiotemporal mapping of population in Europe: The 'ENACT' project in a nutshell. Ispra, Italy: European Commission Joint Research Centre. Available at: https://ec.europa.eu/jrc/en/publication/spatiotemporal-mapping-population-europe-enact-project-nutshell (accessed June 2019).

Bell, M. 2001. "Understanding circulation in Australia: Presidential Address." Journal of Population Research 18(1): 1-18. DOI: https://doi.org/10.1007/BF03031952.

Bell, M. 2004. "Measuring temporary mobility: dimensions and issues." Cauthe Conference, 10-13 February, 2004, Brisbane, Australia: Council for Australasian Tourism and Hospitality Education.

Bell, M. 2015. "W(h)ither the Census?” Australian Geographer 46(3): 299-304. DOI: https://doi.org/10.1080/00049182.2015.1058320.

Bell, M., M. Blake, P. Boyle, O. Duke-Williams, P. Rees, J. Stillwell, and G. Hugo. 2002. "Cross-national comparison of internal migration: issues and measures." Journal of the Royal Statistical Society A 165(3): 435-464. DOI: https://doi.org/10.1111/1467985X.t01-1-00247.

Bell, M. and D. Brown. 2006. "Who are the visitors? Characteristics of temporary movers in Australia." Population, Place and Space 12(2): 77-92. DOI: https://doi.org/ 10.1002/psp.390. 
Bell, M. and G. Ward. 1998. "Patterns of temporary mobility in Australia: evidence from the Census." Australian Geographical Studies 36(1): 58-81. DOI: https://doi.org/ 10.1111/1467-8470.00039.

Bell, M. and G. Ward. 2000. "Comparing temporary mobility with permanent migration." Tourism Geographies 2(1): 87-107. DOI: https://doi.org/10.1080/146166800363466.

Bengtsson, L., X. Lu, A. Thorson, R.S Garfield, and J. von Schreeb. 2011. "Improved Response to Disasters and Outbreaks by Tracking Population Movements with Mobile Phone Network Data: A Post-Earthquake Geospatial Study in Haiti." PLOS Medicine 8(8): e1001083. DOI: https://doi.org/10.1371/journal.pmed.1001083.

Burleigh, M. 2018. "The physically present population." Australian Population Association Conference, 18-20 July, Darwin, Australia: Australian Population Association.

CBS. n.d. "How many people here?". Statistics Netherlands (CBS). Available at: https://www.cbs.nl/en-gb/our-services/innovation/project/how-many-people-here(accessed April 2019).

Chapman, M. 1978. "On the Cross-Cultural Study of Circulation." International Migration Review 12 (4, Special Issue: Illegal Mexican Immigrants to the United States): 559-569. DOI: https://doi.org/10.1177/019791837801200406.

Chapman, M. and R.M. Prothero. 1983. "Themes on circulation in the third world." International Migration Review 17(4): 597-631. DOI: https://doi.org/10.1177/ 019791838301700402.

Charles-Edwards, E., M. Bell, and D. Brown. 2008. "Where people move and when: temporary population mobility in Australia." People and Place 16(1): 21-30. Available at: https://search.informit.com.au/documentSummary; $\mathrm{dn}=157293264384755$;res= IELHSS.

Charles-Edwards, E. and M. Bell. 2015. "Seasonal Flux in Australia's Population Geography: Linking Space and Time.” Population, Space and Place 21(2): 103-123. DOI: https://doi.org/10.1002/psp.1814.

Cook, T. 1996. Demography Working Paper 1996/4 - When ERPs aren't Enough, 1996, Catalogue no 3112.0. Canberra: Australian Bureau of Statistics. Available at: https://www.abs.gov.au/ausstats/abs@.nsf/mf/3112.0 (accessed March 2019).

Cook, T. 1998. "Overnight visitor counts in Australia and their implications for population estimation.” People Place 6(1): 60-70.

CSO. 2017. Census of Population 2016 - Profile 11 Employment, Occupations and Industry. Cork, Ireland: Central Statistics Office, Ireland. Available at: https://www.cso.ie/en/csolatestnews/presspages/2017/census2016profile11 employmentoccupationsandindustry/ (accessed March 2019).

Davis, A. 2011. "On constructing ageing rural populations: 'Capturing' the grey nomad." Journal of Rural Studies 27(2): 191-199. DOI: https://doi.org/10.1016/j.jrurstud. 2011.01.004.

Deville, P., C. Linard, S. Martin, M. Gilbert, F.R. Stevens, A.E. Gaughan, V.D. Blondel, and A.J. Tatem. 2014. "Dynamic population mapping using mobile phone data." Proceedings of the National Academy of Sciences 111(45): 15888-15893. DOI: https://doi.org/10.1073/pnas.1408439111. 
Edmondson, B. and Nantucket Data Platform team. n.d. Making It Count. A Data-Driven Look at Nantucket's Dynamic Population. Nantucket: Nantucket Data Platform.

Halford, K. 2018. How will my divorce affect my kids? The Conversation (September 11, 2018). Available online: http://theconversation.com/how-will-my-divorce-affect-mykids-101594 (accessed April 2019).

Hanson, J. and M. Bell. 2007. "Harvest trails in Australia: patterns of seasonal migration in the fruit and vegetable industry." Journal of Rural Studies 23: 101-117. DOI: https://doi.org/10.1016/j.jrurstud.2006.05.001.

Happel, S.K. and T.D. Hogan. 2002. "Counting snowbirds: the importance of and the problems with estimating seasonal populations." Population Research and Policy Review 21: 227-240. DOI: https://doi.org/10.1023.

Houghton, D. 1993. "Long distance commuting; a new approach to mining in Western Australia." Geographical Journal 159(3): 281-290. DOI: https://doi.org/10.2307/ 3451278.

Hugo, G. and K. Harris. 2013. Time and tide: moving towards an understanding of temporal population changes in coastal Australia. Adelaide: The University of Adelaide. Available at: http://www.esc.nsw.gov.au/living-in/about/community-profileand-population-forecasts/sea_change_taskforce_report_29_april_2013.pdf (accessed January 2019).

Ilves, M. and E. Karus. 2014. "Feasibility study on the use of mobile positioning data for tourism statistics." Quarterly Bulletin of Statistics Estonia 2(14):27. Available at: https://www.stat.ee/publication-2014_quarterly-bulletin-of-statistics-estonia-2-14.

Kounadi, O., A. Ristea, M. Leitner, and C. Langford. 2018. "Population at risk: using areal interpolation and Twitter messages to create population models for burglaries and robberies." Cartography and Geographic Information Science 45(3): 205-220. DOI: https://doi.org/10.1080/15230406.2017.1304243.

Kukutai, T., V. Thompson, and R. McMillan. 2014. "Whither the census? Continuity and change in census methodologies worldwide, 1985-2014." Journal of Population Research 32: 3-22. DOI: https://doi.org/10.1007/s12546-014-9139-z.

Markham, F., J. Bath, J. Taylor, and B. Doran. 2013. New directions in indigenous service population estimation, CAEPR Working Paper No. 88/2013. Canberra: Centre for Aboriginal Economic Policy Research. Aavilable at: https://openresearch-repository. anu.edu.au/bitstream/1885/147837/1/WP88_Markham_et_al_Service_delivery_0.pdf (accessed January 2019).

McKenzie, F. and S. Canterford. 2018. Demographics for bushfire risk analysis: regional Victoria and peri-urban Melbourne. Melbourne: Department of Environment, Land, Water and Planning. Available at: https://www.planning.vic.gov.au/_data/assets/pdf_ file/0035/97685/Demographics-for-Bushfire-Risk-Analysis-web.pdf (accessed October 2018).

McKercher, B. 2018. "The impact of distance on tourism: a tourism geography law." Tourism Geographies 20(5): 905-909. DOI: https://doi.org/10.1080/14616688.2018. 1434813.

Mitchell, J.C. 1969. "Structural plurality, urbanization and labour circulation in Southern Rhodesia." In Migration, edited by J.A. Jacksons: 156-180. London: Cambridge University Press. 
Müller, D.K., C.M. Hall, and D. Keen. 2004. "Second home tourism impact, planning and management." In Tourism, mobility and second homes: between elite landscape and common ground, edited by C.M. Hall and D.K. Müller: 15-32. Clevedon: Channel View Publications.

ONS. 2014. 2011 Census: Workplace Population Analysis. Newport, UK: Office for National Statistics. Available at: https:/www.ons.gov.uk/peoplepopulationandcommunity/populationandmigration/populationestimates/articles/workplacepopulationanalysis/2014-05-23 (accessed March 2019).

ONS. 2017. Annual assessment of ONS's progress towards an Administrative Data Census post-2021. Newport, United Kingdom: Office of National Statistics. Available at: https://www.ons.gov.uk/census/censustransformationprogramme/administrativedatacensusproject/administrativedatacensusannualassessments/annualassessmentofonssprogresstowardsanadministrativedatacensuspost2021 (accessed March 2019).

Paris, C., C. Thredgold, B. Jorgensen, and J. Martin. 2014. Second homes and changing populations: Impacts and implications for local government in South Australia. Adelaide: Centre for Housing, Urban and Reginal Planning (CHURP), University of Adelaide. Available at: http://www.lga.sa.gov.au/webdata/resources/project/2013.35__Second_homes_and_changing_populations_-_Impacts_and_implications_for_local_ government_in_SA.pdf (accessed March 2019).

Plane, D.A. and G.F. Mulligan. 1997. "Measuring spatial focusing in a migration system." Demography 34(2): 251-262. DOI: https://doi.org/10.2307/2061703.

Planning Information and Forecasting Unit. 2006. Towards estimates of service populations to inform planning in small areas. Brisbane: Queensland Department of Local Government, Planning, Sport and Recreation.

Prothero, R.M. and M. Chapman. 1985. Circulation in Third World countries. Boston: Routledge.

QGSO. 2018. Bowen Basin population report, 2018. Brisbane: Queensland Treasury.

Raymer, J., P. Rees, and A. Blake. 2015. "Frameworks for Guiding the Development and Improvement of Population Statistics in the United Kingdom." Journal of Official Statistics 31(4): 699-722. DOI: https://doi.org/10.1515/jos-2015-0041.

Rees, P.H. and A.G. Wilson. 1973. "Accounts and Models for Spatial Demographic Analysis I: Aggregate Population.” Environment and Planning A: Economy and Space 5(1): 61-90. DOI: https://doi.org/10.1068/a050061.

Ruotsalainen, K. 2018. "Techniques for administrative data sources integration in statistical registers." ESTP - Moving towards register based statistical system Valencia, Spain, 12-14 September 2018.

SGS Economics and Planning. 2007. Impacts of Coastal Population Fluctuations. Melbourne: Report prepared for Department of Sustainability and Environment, Victorian Government.

Smith, S.K. 1989. "Toward a methodology for estimating temporary residents." Journal of the American Statistical Association 84(406): 430-436. DOI: https://doi.org/ $10.2307 / 2289926$.

Smith, S.K. 1994. "Estimating temporary populations." Applied Demography 9(1): 4-7. StatsNZ. 2012. "Using cellphone data to measure population movements." Wellington: Statistics New Zealand. Available at: https://www.google.com/url?sa=t\&rct= 
$\mathrm{j} \& \mathrm{q}=\& \mathrm{esrc}=\mathrm{s} \& \operatorname{source}=$ web $\& \mathrm{~cd}=1 \& \mathrm{ved}=2 \mathrm{ahUKEwitwO6BwdvkAhUGILcAHU}$ 9KBYMQFjAAegQIABAC\&url=http $\% 3 \mathrm{~A} \% 2 \mathrm{~F} \% 2 \mathrm{Farchive}$.stats.govt.nz\%2F \% 2Fmedia $\% 2$ FStatistics $\% 2$ Fservices $\% 2$ Fearthquake-info $\% 2$ Fusing-cellphone-datameasure-pop-movement.pdf\&usg=AOvVaw1vjQVs2_SDGgvNrhlHNwlb (accessed April 2019).

StatsNZ. 2015. "Service Population Concept." Wellington: Statistics New Zealand, Available at: http://datainfoplus.stats.govt.nz/item/nz.govt.stats/66ea8a7a-f1c7-4cbc80cd-75b5a018df68/0/ (accessed April 2019).

Swanson, D.A. and J. Tayman. 2011. "On Estimating a De Facto Population and its Components." Review of Economics \& Finance. Available at: http://www.bapress.ca/ Journal-5/On\%20Estimating $\% 20 \mathrm{a} \% 20$ De $\% 20$ Facto $\% 20$ Population $\% 20$ and $\% 20$ Its $\%$ 20Components\%20By\%20David\%20A.\%20Swanson.pdf.

Tam, S.M. and F. Clarke. 2015. Big Data, Statistical Inference and Official Statistics, Calalogue no. 1351.0.55.054. Canberra: Australian Bureau of Statistics. Available at: https://www.abs.gov.au/ausstats/abs@.nsf/mf/1351.0.55.054 (accessed March 2019).

Taylor, J. and M. Bell. 2012. "Towards comparative measures of circulation: Insights from Indigenous Australia.” Population, Space and Place 18(5): 567-578. DOI: https:// doi.org/10.1002/psp.695.

Taylor, J. 1986. "Measuring circulation in Botswana." Area 18(3): 203-208. https://www.jstor.org/stable/20002342.

Theobold, W.F. 2005. "The meaning, scope, and measurement of travel and tourism." In Global Tourism, edited by W.F. Theobold. Burlington, MA: Elsevier Science.

Tourism Research Australia. 2018. Travel by Australians. Canberra: Austrade.

United Nations. 2017. Principles and Recommendations for Population and Housing Censuses. New York: Department of Economic and Social Affairs Statistics Division.

U.S. Census Bureau. 2018. Understanding and Using American Community Survey Data: What All Data Users Need to Know. Washington D.C.: U.S. Department of Commerce. Vandenbroucke, J.P. and N. Pearce. 2012. "Incidence rates in dynamic populations." International Journal of Epidemiology 41: 1472-1479. DOI: https://doi.org/10.1093/ ije/dys 142 .

Williams, A.M. and C.M. Hall. 2000. "Tourism and migration: New relationships between production and consumption.” Tourism Geographies 2(1): 5-27. DOI: https://doi.org/ 10.1080/146166800363420.

Wilson, R., E. zu Erbach-Schoenberg, M. Albert, D. Power, S. Tudge, M. Gonzalez, S. Guthrie, H. Chamberlain, C. Brooks, C. Hughes, L. Pitonakova, C. Buckee, X. Lu, E. Wetter, A. Tatem, and L. Bengtsson. 2016. "Rapid and Near Real-Time Assessments of Population Displacement Using Mobile Phone Data Following Disasters: The 2015 Nepal Earthquake" PLOS Currents Disasters 24(1). DOI: https://doi.org/10.1371/ currents.dis.d073fbece328e4c39087bc086d694b5c.

Zelinsky, W. 1971. "The hypothesis of the mobility transition." Geographical Review 61(2): 219-249. DOI: https://doi.org/10.2307/213996.

Received April 2019

Revised July 2019

Accepted September 2019 